\title{
Identifying the gaps, reducing the waste, and setting priorities in Cochrane gynaecology research
}

\author{
Marian Showell ${ }^{1}$, Devanshi Jani ${ }^{2}$, Cindy Farquhar ${ }^{1}$, and Vanessa Jordan $^{1}$ \\ ${ }^{1}$ The University of Auckland Faculty of Medical and Health Sciences \\ ${ }^{2}$ The University of Auckland
}

September 25, 2021

\begin{abstract}
Objective The aim of this project was to identify gaps and research waste in the dissemination of Cochrane gynaecology evidence in the Cochrane database of systematic reviews (CDSR). Design A research article Setting The Cochrane Gynaecology and Fertility (CGF) Group's specialised register of random controlled trials (RCTs). Sample Trials looking at benign gynaecological conditions, contained in the CGF specialised register, published between the years 2010-2011. Methods Gynaecology trials from the CGF specialised register were matched, by the specific gynaecological issue and treatment, to existing Cochrane reviews. Unmatched trials were categorised to develop and prioritise new review topics. Main outcome measures Proportions Results 740 trials, published from 2010 to 2011, were exported from the specialised register, after removing duplicates and out of scope trials, 185 of these trials were found to be already included in Cochrane reviews. 422 trials were found to be unused, however $192(26 \%)$ of these could be included in an existing CGF SR if it were updated. 230 trials (32\%) were not matched to any review title and from these 21 new review titles were developed. The topic with the largest number of associated 'unused' trials, was 'Plant and herbal extracts for symptoms of menopause'. Conclusions This project was used to consider unused trials, prioritise new review topics and identify those reviews that need to be updated, thereby identifying the gaps in evidence for women with gynaecological problems.
\end{abstract}

Identifying the gaps, reducing the waste, and setting priorities in Cochrane gynaecology research: Research article

*Showell $\mathrm{MG}^{1}$, Jani $\mathrm{D}^{1}$, Farquhar $\mathrm{CM}^{1}$, Jordan $\mathrm{VMB}^{1}$

1 Department of Obstetrics and Gynaecology, University of Auckland, Auckland NZ, 1142

Contact author: Marian Showell, Department of Obstetrics and Gynaecology, University of Auckland, Auckland NZ, 1142. Phone: +64 (09) 92389492, Email: m.showell@auckland.ac.nz

Running title: Identifying the gaps in gynaecology research

ORCHID ID: 0000-0002-1227-4303

\section{Abstract}

\section{Objective}

The aim of this project was to identify gaps and research waste in the dissemination of Cochrane gynaecology evidence in the Cochrane database of systematic reviews (CDSR).

\section{Design}

A research article 


\section{Setting}

The Cochrane Gynaecology and Fertility (CGF) Group's specialised register of random controlled trials (RCTs).

\section{Sample}

Trials looking at benign gynaecological conditions, contained in the CGF specialised register, published between the years 2010-2011.

\section{Methods}

Gynaecology trials from the CGF specialised register were matched, by the specific gynaecological issue and treatment, to existing Cochrane reviews. Unmatched trials were categorised to develop and prioritise new review topics.

\section{Main outcome measures}

Proportions

\section{Results}

740 trials, published from 2010 to 2011, were exported from the specialised register, after removing duplicates and out of scope trials, 185 of these trials were found to be already included in Cochrane reviews. 422 trials were found to be unused, however $192(26 \%)$ of these could be included in an existing CGF SR if it were updated. 230 trials (32\%) were not matched to any review title and from these 21 new review titles were developed. The topic with the largest number of associated 'unused' trials, was 'Plant and herbal extracts for symptoms of menopause'.

\section{Conclusions}

This project was used to consider unused trials, prioritise new review topics and identify those reviews that need to be updated, thereby identifying the gaps in evidence for women with gynaecological problems.

\section{Keywords}

research waste, gaps, gynaecology, randomized controlled trials, systematic reviews, prioritisation.

\section{Tweetable abstract}

Research dissemination in gynaecology could be improved by ensuring existing Cochrane reviews are updated and creating new Cochrane reviews to include unused primary evidence.

\section{Introduction}

Cochrane aims to produce high quality, rigorous health care evidence to inform clinical practice by the production and dissemination of systematic reviews (SRs), network meta-analyses and overviews ${ }^{(1)}$. Cochrane reviews are used in international guidelines, pathways and by international institutions such as the WORLD Health Organisation. Cochrane disseminates RCT evidence to these organisations and the Gynaecology and Fertility Group (CGF), is one of 53 Cochrane review groups responsible for this dissemination through the production of $\mathrm{SRs}^{(2)}$.

To facilitate and support the production of SRs, the CGF maintains a specialised database containing over 20,000 randomised controlled trials (RCTs) which are incorporated into SRs by review authors. The trials come from various sources, including weekly email alerts from MEDLINE, Embase, CINAHL and PsycINFO, handsearching of conference abstracts and journal alerts. This database is used for research projects ${ }^{(3-5)}$ and is imported into CENTRAL on a regular basis ${ }^{(6)}$.

The CGF Register of trials is an asset, and the best way for RCTs to add to the evidence base is through incorporation into Cochrane SRs. The CGF specialised register shows that approximately 480 benign gynaecology trials are published each year ${ }^{(2)}$. However, we had no data on whether these trials were incorporated 
in Cochrane SR's. A project carried out by the Cochrane Acute Respiratory Infections Group found that $41 \%$ of the RCTs in this field were not being used in Cochrane SRs ${ }^{(7)}$

To negate waste and increase the impact of research in women's health we need priority setting exercises for gynaecology uncertainties, that include all stakeholders ${ }^{(8)}$. However, a SR evaluating these studies in women's health $^{(9)}$ found that benign gynaecology was vastly under-represented. Endometriosis was the only area where the top ten priorities had been published ${ }^{(10)}$.

Unused research comes with huge costs, not only in monetary value but more importantly, in ethical cost, in terms of the time and potential risk for the people who volunteer to be randomised into the trials ${ }^{(11)}$. People become involved in trials for various reasons but an important one is that their experience will help improve the health of others ${ }^{(12-14)}$. Ethically, it is important that the information gained from these trials contributes to the evolution of healthcare ${ }^{(15)}$.

The aim of this project was to identify gaps and extent of research waste due to the lack of dissemination of gynaecology evidence in the Cochrane database of systematic reviews (CDSR).

\section{Methods}

All gynaecology RCTs with a date range from 2010-2011 were exported from the CGF specialised register (a bibliographic management database using a ProCiteß platform). This database contains benign gynaecology and fertility trials. The gynaecology trials are coded in the database with all the varying conditions and treatments around gynaecology, and the fertility trials are coded simply with the term 'subfertility' (along with other conditions and interventions) so the search used a strategy of "does not contain" the keyword "subfertility", and this provided the gynaecology cohort of trials.

A two-year time-period was a pragmatic decision and was chosen to give an indication of the scope of the problem. We considered that the time lag, from 2011 to present, should have allowed enough time for the trials to be incorporated into the appropriate SRs.

The list of selected RCTs was exported from a ProCite@ database into EndNoteß (reference management systems), then the text file was imported into an Excel@ spreadsheet - the 'master sheet'. Trials were then excluded if they were either not in the scope of this project or were an inappropriate publication type, these included letters, authors' replies, and errata. The scope of this project includes RCTs that look at interventions for benign gynaecological health issues. The conditions of benign gynaecology included menopause, gynaecological surgery, polycystic ovary syndrome (PCOS), painful menstruation, endometriosis, adenomyosis, dysfunctional uterine bleeding, fibroids, premenstrual syndrome, disorders of menstrual cycle, chronic pelvic pain and hyperandrogenism. The interventions for these conditions included medicines, alternative therapies, lifestyle interventions, psychological and physical therapies and surgery.

The CENTRAL Register of Studies (CRS Web), a web-based repository of Cochrane trials, which records links between trials in the repository and Cochrane reviews, was searched by trial's title and/or author's name to discover whether it had been used in a Cochrane review.

Trials were coded as 'used' or 'unused', if the trial had been linked to a Cochrane review (used), we then noted if the trial was in the included, excluded, awaiting assessment, or the ongoing trial sections of the Cochrane SR. The 'used' or 'unused' decisions were double-checked by manually searching the reference sections of appropriate systematic reviews in the Cochrane library.

The unused trials were then categorised first by population (health condition), and then by specific interventions. Following the coding of trials based on population and intervention, trials were checked against existing Cochrane review titles to determine if they could be included in an updated version of the review, and if so, they were coded as 'existing reviews". The unused trials that were categorised as 'out of scope' (either not an RCT or not in the gynaecology scope) or 'duplicate' (either the same publication appearing in the database twice or a separate publication of the same trial, and in this case, we only used the primary publication) were excluded. 
Unused trials that could be considered for new review titles, categorised into their health condition and specific intervention, were then used to formulate a list of potential new titles for CGF reviews. From this list, new topics were prioritised if they had three or more associated unused trials. The rationale for this for priority setting decision was that a SR would require analysis of least two RCTs allowing for one to be potentially excluded from the SR.

\section{Results}

Between 2010 and 2011, 740 published trials of interventions for benign gynaecology conditions were found by searching the CGFG specialised register. Of these 740 trials, we excluded 15, nine of these were secondary publications and six were fertility trials and therefore out of scope.

Of the remaining 725, CRS Web classified 159 trials as used, and 566 trials as unused (78\%) in CGF SRs. Of these unused trials, a further 95 publications were excluded: 73 of these were subsequent publications of the same trials and 22 were found to be out of scope or protocols.

The 471 unused trials were then categorised into 11 gynaecological health conditions: menopause, gynaecological surgery, PCOS, painful menstruation, endometriosis, heavy menstrual bleeding, fibroids, premenstrual syndrome, cyclic disorders (i.e., amenorrhoea), chronic pelvic pain and hyperandrogenism and these conditions were then linked to six intervention groups: medical, alternative therapy, lifestyle, psychological, surgery and physical therapies (table 1). During this process a further 23 trials were excluded due to being out of scope or found to be used in a CGF SR. We also hand-searched the reference sections of Cochrane SRs with similar intervention and populations to double check these used/unused decisions, and we found that 26 of these trials were used by other Cochrane groups, most commonly in Cochrane Anaesthesia reviews, so these were then moved to the 'used' trials cohort. Therefore 422 trials of the total 725, were classified as unused (32\%) by any Cochrane systematic reviews. 192 of these could be linked to an existing Cochrane SR and could be used if or when the review was updated (figure 1).

Grouping by population showed that the vast majority of unused trials were in the 'menopause' category followed by surgery for benign gynaecological conditions (table 2). Medical interventions (generally one medical intervention compared to another) and alternative therapy were the most common interventions in the menopause group, and medical therapy in the gynaecological surgery group (generally the use of different analgesics and anaesthetics) (figure 2).

There are 104 potentially new topics for Cochrane systematic reviews from the 230 unused trials to become SR titles (figure 3), however only 22 of these topics captured three or more trials, the number considered to be the minimum required to produce a useful SR. Menopause had seven new topics, with 3 or more associated trials, the largest being 'Plant and herbs for menopausal symptoms. Gynaecological surgery had six new topics, the largest was 'Pregabalin (pre-surgery) for analgesia post abdominal hysterectomy (table $3)$.

\section{Discussion}

\section{Main Findings}

Over half of the trials (58\%) in the specialised register published from $2010-2011$ were not being disseminated in Cochrane SRs and as such could be considered wasted evidence. Of the unused trials $45 \%$ of these could be used if an existing review was updated. Cochrane review authors are encouraged to update their review every two years ${ }^{(16)}$ and it is surprising to find a large number of trials of this age that have not been incorporated into CGF SRs. In this project we have identified the reviews that each of these trials could fit and they will be prioritised and updated accordingly.

\section{Strengths and limitations}

Here we have answered a question regarding the numbers and scope of gynaecology trials that were not being included in Cochrane systematic reviews, however due to time restraints we were limited in practical terms, 
to only being able to study those trials published from 2010-2011, and we did not have the opportunity to match these unused trials to non-Cochrane reviews.

However, this pragmatic approach allowed for a comprehensive collection of RCTs in gynaecology to be investigated in-depth, in terms of the population, intervention and inclusion status in any existing

Cochrane SR.

\section{Interpretation}

The number of unused trials (32\%) compares unfavourably to the audit of the fertility trials over the same time period where only $14 \%$ of all trials in the specialised register being classified as unused ${ }^{(17)}$. The Cochrane Acute Respiratory Infections Group (CARIG) paper ${ }^{(7)}$ that found $41 \%$ of the RCTs in their specialised register were unused, although this difference could be attributed to the longer time-period of this audit, as the CARIG group incorporated 5285 trials from 1930 to 2014.

Trials using plant and herbal remedies for menopausal symptoms were the most commonly unused trials, this does not reflect the increasing consumer interest in complementary medicine ${ }^{(18)}$. The wastage of these unused trials is an important ethical consideration for the women enrolled in these trials. In the future we need to ensure that their sacrifice is not wasted, and they would be willing to participate in future trials $(11,15)$.

One of the top ten questions for endometriosis in the priority setting partnerships ${ }^{(8-10)}$ : "what are the outcomes and/or success rates for surgical or medical treatments which aim to cure or treat endometriosis rather than manage it?", fits broadly into our identified SR topic for endometriosis 'Surgical techniques for laparoscopic resection of endometrioma'.

In accordance with the recommendations of priority setting exercises ${ }^{(8)}$, the next step for prioritisation of topics in this project is to develop a short survey to be disseminated to healthcare consumers (via task exchange) and to the CGF editors for prioritisation of the new review topics.

\section{Conclusions}

This project developed new review topics and identified reviews that need to be updated, thereby identifying research that is not being disseminated resulting in research waste and gaps in the evidence for women with benign gynaecology conditions.

\section{Acknowledgements}

We would like to acknowledge The University of Auckland, Department of Obstetrics and Gynaceology, for awarding Devanshi Jani a summer studentship position which enabled us to complete this project.

\section{Disclosure of Interests}

The authors on this paper do not have any financial, personal, political, intellectual or religious conflicts of interest.

\section{Contribution to Authorship}

Marian Showell, Vanessa Jordan and Cindy Farquhar all had a role in the conception, planning, carrying out, analysing and writing up of the work. Devanshi Jani had a role in planning, carrying out, extracting the data, analysing and writing up of the work. All authors commented on drafts and the final document.

\section{Funding}

Funding was not gained or sought for this study.

\section{References}

1. Cochrane. About us https://wwwcochraneorg/about-us. Accessed 1 July 2020. 
2. Cochrane. Welcome Gynaecology and Fertility Group. https://cgfcochraneorg/welcome Accessed 1 July 2020 .

3. Farquhar CM, Showell MG, Showell EAE, Beetham P, Baak N, Mourad S, et al. Clinical trial registration was not an indicator for low risk of bias. Journal of clinical epidemiology. 2017;84:47-53.

4. Farquhar CM, Showell MG, Showell EAE, Beetham P, Baak N, Mourad S, et al. Clinical trial registration in fertility trials - a case for improvement? Hum Reprod. 2017;32(9):1827-34.

5. Wilkinson J, Roberts SA, Showell M, Brison DR, Vail A. No common denominator: a review of outcome measures in IVF RCTs. Hum Reprod. 2016;31(12):2714-22.

6. Cochrane Library. How Central is created 2020 [cited 20202 December]. Available from: https://www.cochranelibrary.com/central/central-creation

7. Alloo J, Vallath S, Del Mar C, Carter M, Thorning S, Clark J. Determining the gaps between Cochrane reviews and trials of effectiveness of interventions for acute respiratory infections: an audit. Systematic reviews. 2017;6(1):82.

8. Alliance JL. The James Lind Alliance Priority Setting Partnerships South Hampton: National Institue for HealthResearch Evaluation Trials and Coordinating Centre; 2018 [Accessed in August 2018]. Available from: https://www.jla.nihr.ac.uk/priority-setting-partnerships/

9. Graham L, Illingworth BJG, Showell M, Vercoe M, Farquhar CM, Crosbie EJ, et al. Research priority setting in women's health: a systematic review. BJOG: An International Journal of Obstetrics and Gynaecology. 2020;127(6):694-700.

10. Horne AW, Abokhrais IM, Hogg L, Saunders PTK. Top ten endometriosis research priorities in the UK and Ireland. The Lancet. 2017;389(10085):2191-2.

11. Macleod MR, Michie S, Roberts I, Dirnagl U, Chalmers I, Ioannidis JP, et al. Biomedical research: increasing value, reducing waste. Lancet. 2014;383(9912):101-4.

12. Jenkins VA, Fallowfield LJ. For the Benefit of Others: Reasons Why Women with Breast Cancer Participate in RCTs. Breast care (Basel, Switzerland). 2015;10(2):88-93.

13. Minogue V, Cooke M, Donskoy AL, Vicary P, Wells B. Patient and public involvement in reducing health and care research waste. Research involvement and engagement. 2018;4:5.

14. Oliver DP, Benson JJ, Ulrich C, Washington KT, Rolbiecki AJ, White P, et al. Perceived Benefits and Burdens of Participation for Caregivers of Cancer Patients in Hospice Clinical Trials: A Pilot Study. Journal of pain and symptom management. 2020.

15. Ioannidis JPA, Greenland S, Hlatky MA, Khoury MJ, Macleod MR, Moher D, et al. Increasing value and reducing waste in research design, conduct, and analysis. Lancet (London, England). 2014;383(9912):166-75.

16. Higgins JPT, Thomas J, Chandler J, Cumpston M, Li T, Page MJ, et al. Cochrane Handbook for Systematic Reviews of Interventions version 6.1 (updated September 2020). Cochrane, 2020. Available from wwwtrainingcochraneorg/handbook [Internet]. 2020.

17. Showell M, Stedman K, Farquhar C, Jordan-Cole V. Using the Cochrane Register of Studies to identify the evidence gaps in Fertility Cochrane systematic reviews. Virtual conference. University of Auckland2020.

18. Liu L, Tang Y, Baxter GD, Yin H, Tumilty S. Complementary and alternative medicine - practice, attitudes, and knowledge among healthcare professionals in New Zealand: an integrative review. BMC complementary medicine and therapies. 2021;21(1):63.

Table 1. Number of RCTs not used in SRs - classified by Population and Intervention topics 


\begin{tabular}{|c|c|c|c|c|c|c|c|}
\hline Population (health condition) & Medical & Alternative & Lifestyle & Psychological & Surgery & Physical & Tot: \\
\hline Menopause & 87 & 69 & 40 & 3 & & 6 & 205 \\
\hline Gynaecological Surgery & 75 & 3 & & & 42 & 2 & 122 \\
\hline Polycystic Ovary Syndrome & 31 & 10 & 3 & & & & 44 \\
\hline Painful Menstruation & 7 & 17 & 1 & 1 & & 1 & 27 \\
\hline Endometriosis/Adenomyosis & 14 & 5 & & & 5 & & 24 \\
\hline Dysfunctional Uterine Bleeding & 10 & 2 & & & 3 & & 15 \\
\hline Fibroids & 5 & & & 1 & 7 & & 13 \\
\hline Premenstrual Syndrome & 2 & 10 & & & & & 12 \\
\hline Disorders of Menstrual Cycling & 4 & & & & & & 4 \\
\hline Chronic Pelvic Pain & 1 & & & & & 2 & 3 \\
\hline Hyperandrogenism & 2 & & & & & & 2 \\
\hline Total & 238 & 116 & 44 & 5 & 57 & 11 & 471 \\
\hline
\end{tabular}

Table 2. RCTs matched to existing reviews across Cochrane Entities or for the creation of new review topics

\begin{tabular}{lll}
\hline Populations & Trials that could be included in an existing review & Trials for new review top \\
\hline Menopause & $65(34 \%)$ & $65(34 \%)$ \\
Gynaecological Surgery & $61(32 \%)$ & $61(32 \%)$ \\
Polycystic Ovary Syndrome & $12(6 \%)$ & $12(6 \%)$ \\
Painful Menstruation & $16(8 \%)$ & $16(8 \%)$ \\
Endometriosis/Adenomyosis & $13(7 \%)$ & $13(7 \%)$ \\
Heavy menstrual bleeding & $6(3 \%)$ & $6(3 \%)$ \\
Fibroids & $10(5 \%)$ & $10(5 \%)$ \\
Premenstrual Syndrome & $4(2 \%)$ & $4(2 \%)$ \\
Disorders of Menstrual Cycling & $3(2 \%)$ & $3(2 \%)$ \\
Chronic Pelvic Pain & $2(1 \%)$ & $2(1 \%)$ \\
Hyperandrogenism & 0 & 0 \\
Total & $\mathbf{1 9 2}$ & $\mathbf{1 9 2}$ \\
\hline
\end{tabular}

Table 3. New topics created and number of associated trials

\begin{tabular}{ll}
\hline Clinical area & New topic \\
\hline Menopause & Plant and herbal extracts for symptoms of menopause \\
Exercise for cardiac disease risk factors in menopause \\
Diet for cardiac disease risk factors in menopause \\
Plant and herbal extracts for cardiac disease risk factors in menopausal women \\
Diet and exercise for cardiac disease risk factors in menopause \\
Hormone therapy for cardiac disease risk factors in menopause \\
Phytoestrogens for depression and cognition in menopause \\
Transdermal patches for post-operative analgesia following gynaecological surgery \\
Anaesthetics for hysteroscopy, local with inhaled sedation or general \\
Pregabalin (pre surgery) for analgesia post abdominal hysterectomy \\
Regional (spinal, epidural, caudal) versus general anaesthesia in women undergoing a \\
Uterine distention media and pressures for hysteroscopic myomectomy \\
Embolic materials for uterine artery embolisation of uterine fibroids
\end{tabular}




\begin{tabular}{ll}
\hline Clinical area & New topic \\
\hline Polycystic ovary syndrome (PCOS) & $\begin{array}{l}\text { Hormone therapy versus another hormone therapy for women with PCOS } \\
\text { Anti-androgen drugs for women with PCOS not actively trying to conceive } \\
\text { Metformin versus other drugs for women with PCOS }\end{array}$ \\
& $\begin{array}{l}\text { Dietary/Herbal Supplements for women with PCOS } \\
\text { Physical therapy for women with primary dysmenorrhoea }\end{array}$ \\
Painful menstruation & Selective Serotonin Receptor Agonists for women with menstrual related migraine \\
Endometriosis & Surgical techniques for laparoscopic resection of endometrioma \\
Premenstrual syndrome & Herbal/plant extracts for premenstrual syndrome \\
\hline
\end{tabular}

\section{Hosted file}

Figure one Gynae BJOG flow diagram.docx available at https://authorea.com/users/332810/ articles/539106-identifying-the-gaps-reducing-the-waste-and-setting-priorities-incochrane-gynaecology-research

\section{Hosted file}

Figure two Gynae BJOG not used.docx available at https://authorea.com/users/332810/articles/ 539106-identifying-the-gaps-reducing-the-waste-and-setting-priorities-in-cochranegynaecology-research

\section{Hosted file}

Figure three Gynae BJOG number of new.docx available at https://authorea.com/users/332810/ articles/539106-identifying-the-gaps-reducing-the-waste-and-setting-priorities-incochrane-gynaecology-research 